\title{
Resting State fMRI, before and after Scottish rite freemasonry initiation ceremony to get entered apprentice degree in a female
}

\author{
José Luis Mosso Vázquez ${ }^{1 *}$, Carlos Jesús Castañeda González², Dejanira Mosso Lara ${ }^{3}$, Julián Sánchez Cortázar ${ }^{4}$, Roger Antonio Carrillo \\ Mezo $^{5}$, Oscar René Marrufo Melendez ${ }^{5}$, Mayra Ortiz Givaundan ${ }^{3}$, Yolanda Tovar Ortega ${ }^{3}$, Brenda Wiederhold ${ }^{6},{ }^{7}$, Mark Wiederhold $^{6}$ and $^{2}$ \\ Ian Miller ${ }^{6}$
}

${ }^{1}$ Regional Hospital Number 25, Social Security Mexican Institute, México

${ }^{2}$ Pshychiatric Hospital, Fray Bernardino Álvarez, México

${ }^{3}$ Hospital Angeles México, México

${ }^{4}$ Hospital Angeles del Pedregal, Mexico

${ }^{4}$ Neuroimaging Departments, National Institute of Neurology and Neurosurgery, Mexico

${ }^{6}$ The Virtual Reality Medical Center, San Diego CA, USA

${ }^{7}$ Virtual Reality Medical Institute, Brussels, Belgium

\begin{abstract}
Objective. Demonstrate remarkable improving behavior and mood as well as areas brain activation and inhibition changes with resting state before and after Scottish Freemason initiation ceremony in a young Mexican female to get the entered apprentice degree with a medical record with depression, depression, low self-esteem, introvert person, emotionally adaptability since childhood.

Methodology. A Mexican female 30 age participate with written consent. Neuropsychological assessment was done before ceremony on March 28, 2019 and Brain fMRI was made 26 hours before initiation ceremony on March 30, 2019 (phase I). A hermetic Scottish rite ceremony was performed in 4 hours on March 30, 2019 in Alpha and Omega number 33 Lodge Mexico City (phase II) with the permission of Mexican United Female and Regular Grand Lodge, "Alma Mexicana". Second neuropsychology and Brain resting state control also on April 6, 2019 (phase III).

Results. fMRI findings were an active temporal lobe change with low prefrontal lobe activation after ceremony. High activation in superior and middle in temporal gyrus deep activity in anterior lobe in left hemisphere and parietal lobe no activity (Comparative findings with before resting state fMRI). In the rest of brain areas there were not changes as Limbic lobe, gyrus cinguli, epithalamus, thalamus, hypothalamus, pons and brain stem with no activity before and after ceremony. Remarkable findings are in psychometric test, candidate show great changes in his mood, personality, emotions, mind perception of herself, the family and to the society. The most significant change observed is the human figure of the candidate after initiation is the figure of the person comparative with the rain drawing test before the initiation that represent more security.

Conclusions. Candidate didn't need psychological treatment or rehabilitation to improve remarkable emotional disorders. After ceremony we observed improving her emotions, personality giving her security. Resting state fMRI support functional activities in her brain after ceremony in specific brain activation areas as temporal and low activation prefrontal lobes after Scottish rite ceremony. It is clear that all happens probably permanently in the mind of the candidate inside ceremony is in the unconscious if we considered behavior and mood changes after ceremony.
\end{abstract}

\section{Introduction}

Ceremony initiation is a rite or ritual series to entrance into a group or society (as fraternal organization, secret society, religious order, communion, Christian baptism, Christian confirmation, graduation, etc.), in order to transform in which, the initiate is reborn into a new kind of life [1]. Neanderthal specie (500,000 years ago) performed rituals to deities and invented religion and believed in life after death. Homo sapiens (200,000 years ago) continues with this millenary tradition [2].

In Mexican History, Mayas, Aztecs and many indigenous communities performed traditional and sophisticated rituals dedicated to many deities every; day, week, month, holy year, and centuries. Up today many prehispanic rituals are preserved by many indigenous communities [3-6]. After 1519, Mexican prehispanic rituals decreased and European rituals appears as Christians. Over time, around $18^{\text {th }}$ century they were imported many orders in Mexico as freemasonry rituals that impacted in the political life of the country as the Independence and reform laws [7].

${ }^{*}$ Correspondence to: José Luis Mosso Vázquez, Regional Hospital Number 25, Social Security Mexican Institute, México, E-mail: jmosso@up.edu.mx

Key words: initiation, resting state, fMRI, secret society, freemasonry

Received: January 29, 2021; Accepted: February 23, 2021; Published: February 26, 2021 
Many authors as McNamara explains that ritual process involve spiritual possession where is necessary a candidate and the divinity, and between them an intermediate as priest, worshipful, etc. who roll of this intermediate is to provide power from divinity to candidate. Religion experience demonstrate how brain centers and pathways are involved by fMRI. Temporal lobes, gyrus cingula, limbic center, cerebral amygdala are the mean brain areas involved in this religious experience [8-10]. Recently, Mosso et al. demonstrated in a case of spiritual possession during exorcism how temporal lobes are activated and frontal lobes were depressed by resting state fMRI, and there are disconnection of Corpus callosum from both hemispheres [10,11].

Freemasonry is as Secret order Society, really is a Society with secrets that recreate ancient rituals of King Salomon in lodges (Temples) similar architecture as the Temple of Jerusalem with the objective to Worshipful Grand Architect of the Universe (Yahweh God) and become an initiated (Godless man) to serve the humanity and promote a new world order working a love platform and searching the progress for everyone. They preserve the three great moral values originated in the $16^{\text {th }}$ century centuries called; Legalité, Fraternité et Égalité created in French revolution. The first constitution was born in London in 1717 thanks to French and England fraternity [1].

Mexican freemasonry was founded by French immigrants during the second half of the 18th century, (at least 1806). Mexican freemasonry as holder of conservative ideas gathered in lodges of the Scottish rite, while reformists choose the York Rite. Scottish rite became synonymous with Conservatives and York rite as liberals. There exist 3 major rites up today in Mexico, National Mexican Rite, and Ancient and accepted Scottish Rite and York Rite. There are 2 federal Grand lodges. Mexican Grand Lodge of York and Grand Lodge of the Valley of Mexico for males. For women exist the United Female Grand Lodge "Mexican Soul".

Freemasonry and women. Women participated in freemasonry before 18th century. They founded the first grand lodge in England. At the end of 1890, mixed lodges following a standard ritual started to appear in France, and quickly spread to other countries. In this project Mexican United Female and Regular Grand Lodge, "Alma Mexicana" participated and it was founded on 1958 and currently it has 63 lodges in all the country up today (2020). In 2008 there was 42 Grand Lodges with 32000 members in 1050 Lodges in the worldwide in more than 30 countries.

Many highlight members from this Societies with secrets are in politics, culture, philosophy, science, everywhere in the worldwide as; Winston Churchill, George Washington, Neil Armstrong, Napoleon Bonaparte, Benito Juarez, etc.

Rituals include grips, token, passwords, marches, and three ceremonies (We don't have access for more information). The first ceremony (Initiation) is for entered apprentice, the second (The passing degree) for fellow craft and the third (Known as the raising degree) for Master Mason. In this project we include the initiation ceremony to get the first degree of entered apprentice.

The appearance of fMRI, neuroscience is stronger that permit us to know more about anatomy brain, mind and humankind personality [12]. There is much interest to know what's going on with the brain under spiritual practices and intangible phenomena such as altered states of consciousness, possessions, near death experiences, out of the body experiences, etc. Up today there are a huge neuroscience interest and support to explore and explain brain activity in religion without the interest to demonstrate or disprove existence of God, but this knowledge contributes to understand the evolution of Homo sapiens and his future. Scientific theories contribute and support that religion was created by Neanderthal thanks to the discovery of remains as fetal position in the buried, paintings related with worshipful to bears, and small statute of human with head of Lyons. Up today, Homos Sapiens evolution is discovering in the last decades brain areas involved with religion experience and much more. Defense Advanced Research Projects Agency (DARPA) and many institutions in the world has the biggest and most important neurotechnology project since 1970's. The White House announced the Brain initiative in April 2013 where DARPA is the head of the project and there are three phases [12]. The Phase 1. Brain Mapping. This is a huge effort ( $\$ 100$ million per year) from multiple government agencies, most of the money going to National Institutes (NIH). Phase 2: Mapping the Cortical Tracts or white matter - the "Connectome". Is about the connections between the numerous tracts, fasciculus of the brain. The most common imaging is the use of Diffusion Tension Imaging (DTI), and tractography. Phase 3: Brain Machine Interface (BMI). It was started in the early 2000's by DARPA, but many other agencies from other countries are working. The plan is to find where in the brain, the different 'functions' are located (in the Grey Matter). We know roughly where the sensors are located, and out muscle function is located (either of the Sylvan Fissure) and sight (Occiput), but the project is to finely tune where every function is located, especially memory, decision making, consciousness, intelligence, etc. There are huge amount of funding to building devices that will allow us to "read" the brain signals to see if we can "read someone's thoughts" and whether we can create devices to implant into the brain to for controlling - either from the brain to muscles or prostheses, as well as the sensors to send signals to the correct part of the brain.

Other BMI permit us to extract or introduce electrical information to the brain to activate or suppress specific brain areas with health proposals as to move arm and legs in disabled or paralyzed patients (Motor brain areas stimulation), and extract brain information (Energy extractions) into a computer to permit unlocked patients communicate with the outside or to develop brain to brain interface for real time sharing sensorimotor information and navigate guided by remote control into different and distal spaces. Computers can be controlled with our fingers to manipulate mices, head motions, eye movement, but currently we can communicate with computers just with our will, just with the mind [13]. The future of Homo sapiens is exciting with new discoveries because there are the fundamentals to arise our mind functions and potential them to become a superhuman or different Homo sapiens, and new specie. Post humanism is beginning with genome, robotics and meanly with the Brain Computer Interphase, brain implants and brain genetic manipulation. Improve the mind is an ancient proposal of human, natural selection demonstrate how few great initiates, big great scientist have contributed for the good of humanity. Artificial selection is for the future [14,15]. Artificial great initiates, artificial scientist will be everywhere. One of the proposals of Secret societies is to become a human in superhuman as great initiates with natural selection without technology, just jointing brotherhoods minds in rituals or ceremony to activate or deactivate specific brain areas of the initiated. This is our proposal in this project, to explore candidate brain areas with fMRI before, during and after freemasonry rituals. We have consent of Female Mexican freemasonry secret society to make reality this project. 


\section{Methodology}

Young Mexican female candidate participated under consent to get the first degree entered apprentice to the Alpha and Omega Lodge of the Mexican United Female and Regular Grand Lodge, "Alma Mexicana". Neuropsychologist, psychiatric, neurosurgeon, 2 radiologists one physic, and one psychiatric participated also for assessment. Candidate didn't know about resting state, phycology and psychiatric assessments and ceremony appointments. Candidate Medical record. She was born in Mexico City on 1987 (Millennial generation, 1980 to 1999), till 5 years of age she was abandoned 3 days each by her parents that have to work at hospitals as Medical residents. Following III phases descriptions as psychometric and fMRI assessment.

1.- Person in the rain. The "Person under the Rain" test is classified as a projective - graphic test, since it consists of drawing and telling the story of the person who is in the rain. In the words of the manual by Silvia M. Querol and María I. Chaves Paz "In the interpretation of the drawing we seek to obtain the corporal image of the individual under unpleasant, tense conditions, in which the rain represents the disturbing factor, and so on what type of defenses used".

2.- Human figure. The drawing of the human figure generates conscious associations, since it is a direct expression of the body image. The quality of the drawing will reflect the ability of the subject to maintain personal relationships and to submit their self and their interpersonal relationships to a critical and objective evaluation. Other areas that are interpreted through the drawing are those that refer to the concept that the person has about himself, about his sexual role and the attitude he has with himself and with others. The considerations of the drawing that we will comment next is in drawing of the human figure of adults.

3.- HTP (House, Tree, Person). We project parts of our personality that are usually hidden in the unconscious, these parts are reflected in how we draw the different elements of the artistic composition. The important thing in this test, is knowing that there are no right or wrong answers, the results will be more reliable the freer we are in our expression.

4.- Test of the family. This test allows us to know the affective ties, as a relationship with each of the family members that it comes to represent, but without verbal defenses that usually cover all conflicts, being able to see where there is resistance and family concerns.

5.- Tree test. The drawing of the tree is a test of graphical projection launched by Karl Koch, this affirms that the drawing of the tree is a graph less subtle, less elaborated, but that in certain cases allows to see what it does not achieve. This projective test can be used without any resistance to your drawing by children, young people and adults. (Table $1)$.

\section{Phase II (Ceremony)}

A hermetic ceremony was performed on March 30, 2019 for 4 hours in Alma Mexicana Lodge in Mexico City at 18 hours to 22 hours. It was no possible to be into the ceremony for indications of the order.

\section{Phase III (After Ceremony)}

Second psychiatric and neuropsychology assessment were done 7 days after ceremony with the same metrics. Control Resting state was performed in the same hospital by the same researchers on April 6, 2019. Resting state was performed with Phillips MRI equipment, Achieva with release 3.2 .3 software, 3 Teslas and 8 channels antenna
Table 1. Psychometric test before and after initiation ceremony

\begin{tabular}{|c|c|}
\hline Painting test before initiation ceremony & Painting test after initiation ceremony \\
\hline Person under the rain & Human figure \\
\hline Home, Tree, person (HTP) & Family \\
\hline Tree & \\
\hline
\end{tabular}

head. Characteristics process is a block of 32 cuts $4 \mathrm{x} 0 \mathrm{~mm}$ thick. Resting state was performed with no body motions and closed ayes in 6 minutes.

\section{Results}

Psychometric test findings. There was a significant change in the projective tests after the initiation, which mark the personality of the candidate, this change is not a result of work in therapy, nor of any pharmacological treatment, since the time between one session and another was 8 days. The most significant change observed is the human figure of the candidate after initiation compared to the figure of the person in the rain before the initiation.

\section{Before ceremony initiation:}

1.- Person in the rain. In this test the result we obtained is that the candidate has a defensive attitude to criticism, which represses his aggressive thinking and tries to get away from people to avoid conflicts has a great control to reveal emotions, has low self-esteem.

2.- HTP (House, Tree, Person). Introverted person, with problems to interact with other people in new environments, however there are environments in which he feels with a little more support and security, talking about the family part marks a bad family affective environment, as a consequence of a childhood with abandonment events.

He has a great fear of failure, although he is a person who has a lot of permeability before social pressures, about his academic training. He is a person who has a lot of discipline but lacks strength and vitality to reach his goals, which diminishes the desire for expansion.

3.- Tree test. In this test the result that was obtained is that the candidate had a complicated childhood, with some problems of emotional stability which has led to problems of adaptation and confidence in herself, she is very shy. He is an emotional, sensitive person, with a desire to communicate. She has a lot of desire to overcome herself, although when she feels very lost, she tends to get depressed.

\section{After initiation ceremony:}

4.- Human figure. In this test we can observe a person with reference and desires to their future, with the confidence of future, a sensitive person, with desire for dependence and with feelings of strength to fight. The drawing also shows a person with security. Although there are still traits that he has a great need to hide his feelings of insecurity.

5.- Test of the family. In this test it is observed that the relation that it has with the parents is weak with inhibitions of communication, but with the other members it has a stronger relation, with easy communication and feelings of protection and support. In the family context all the characters know their role in the family and the place they occupy, and although in appearance they have a very close relationship, there are moments where the distance and the absence of some members if it comes to affect (Figure 1).

\section{Resting states fMRI findings (Figure 2) (Table 2).}

In a color scale of .4 (low activation) to 0.8 (high activation) and (BC) before ceremony and (AC) after ceremony, brain findings are, Frontal 
Drawings, 24 hours before ceremony

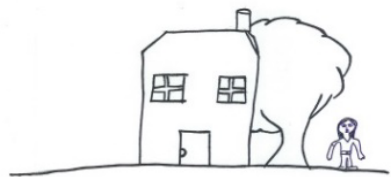

1

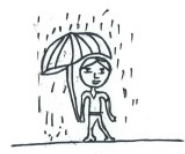

2

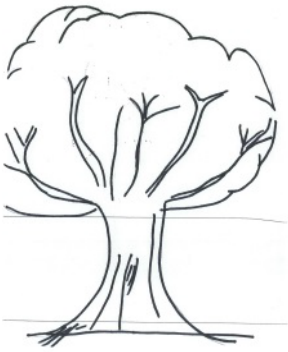

3
Drawings, 6 days after before ceremony

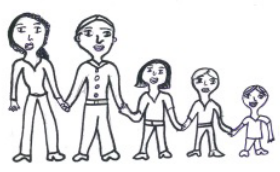

4

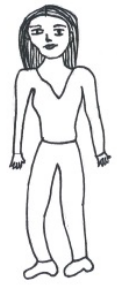

5

Figure 1. Psychometric test. 1. - HTP (house, tree and person) 2. - Person in the rain 3. - Tree 4. - Test of the family 5. - human figure
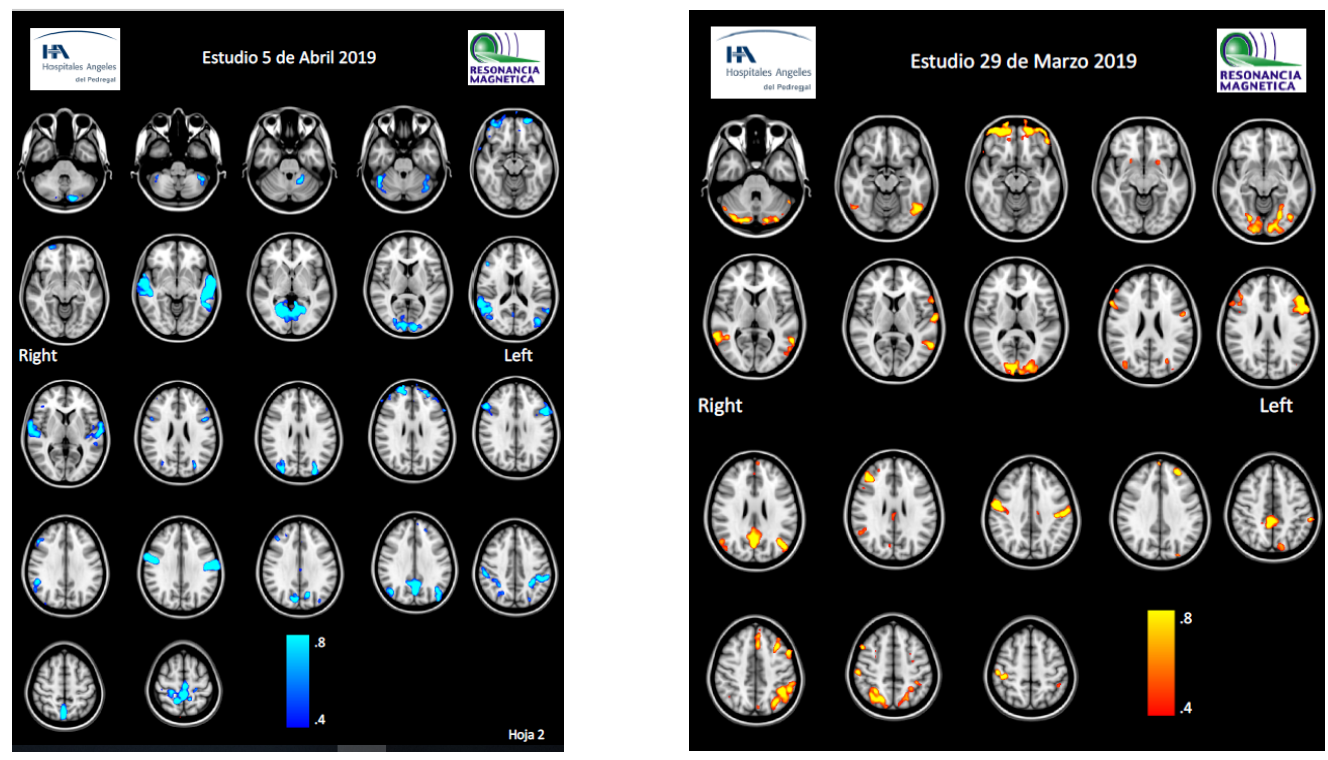

Figure 2. Brain activity one day before ceremony and 5 days after ceremony. Low activity (04), high activity (0.8) 
Table 2. Brain areas activity during fMRI resting state

\begin{tabular}{|c|c|c|}
\hline Brain areas & Before ceremony & After ceremony \\
\hline Frontal lobe & $\begin{array}{l}\text { Active prefrontal area. More activity from the left } \\
\text { hemisphere than the right. }\end{array}$ & Low prefrontal activation (Frontopolar area). \\
\hline Temporal lobe & Small activation in upper left temporal operculum. & High activity in superior and middle temporal gyrus. \\
\hline Occipital lobe & Activity in primary visual area & Activity in primary visual area \\
\hline Parietal lobe & Little activity in the left hemisphere. & No activity \\
\hline Limbic lobe & No activity & No activity \\
\hline Corpus callosum & $\begin{array}{l}\text { Minimum activity in posterior of corpus callosum } \\
\text { (Splenium) }\end{array}$ & No activity \\
\hline Gyrus Cinguli & No activity & No activity \\
\hline $\begin{array}{l}\text { Thalamus Hypothalamus } \\
\text { Epithalamus }\end{array}$ & No activity & No activity \\
\hline Cerebellum & Cortical activity in posterior lobes in both hemispheres. & Deep activity in anterior lobe in left hemisphere. \\
\hline Pons & No activity & No activity \\
\hline Brain stem & No activity & No activity \\
\hline
\end{tabular}

lobe: active prefrontal area with more activity from the left hemisphere than the right $\mathrm{BC}$ and low prefrontal activation in frontopolar area AC. In temporal lobe there are small activity in upper left temporal operculum in BC and High activity in superior and middle temporal gyrus in AC. In occipital lobe there are similar activity in primary visual area $\mathrm{BC}$ and AC. In Parietal lobe there are small activity in left hemisphere $\mathrm{BD}$ and no activity $\mathrm{AC}$. In limbic lobe there are no activity before and after ceremony. In Corpus callosum there are slow activity in splenium (posterior region or corpus callosum) BC, no activity was finding AC. In Gyrus cinguli no found activity BC and AC. There is not activity in thalamus, epithalamus and hypothalamus before and after ceremony. In Cerebellum there are cortical activity in posterior lobes in both hemispheres BC and deep activity in anterior lobe in left hemisphere. Pons and brain stem no activity before and after ceremony.

\section{Conclusions}

In comparative brain images and psychometric tests were find huge and great difference after freemason ceremony initiation in a young female to obtain the entered apprentice degree with Scottish rite in a Mexican female lodge (Mexican Soul Lodge). It is clear that all happens in the mind of the candidate is in the unconscious if we considered behavior and mood changes after ceremony and low activity. With one resting state RS, we cannot give a general conclusion about ceremony initiation phenomena, we just describe our isolated findings that are of our interest because high activation in temporal lobe and slow activity in prefrontal lobe and cerebellum after ceremony were found. RS changes are relevant if we correlate with psychometric test results where candidate demonstrate remarkable changes after ceremony improving in the family and human figure test. Expert opinion said this change takes more time with long phycological therapies and in sometimes with medications support and not in a week period as happens in this case. These findings motivate us to follow up this research in future ceremonies in the same candidate in her progress to fellow craft or the passing degree (second degree) and the raising degree) for Master Mason (third degree). We need a comparative female fMRI and phycological test with no ceremony to make a comparative research in future works and considerer more male and female candidates. Neuroscience is developing new systems to activate or disactivate brain areas using magnetic brain stimulation discovering new anatomicfunctional brain areas as disembodiment (out of the body experience) [16-21]. Brain computer Interphase is discovering how the brain can be used as potential biological machine to perform better human tasks where memory capacity, data information, can be extended [22,23]. Ceremony initiation activate and inhibition brain areas with the support of big mind groups that work with secret rituals to become humans to superhumans. Neuroscience try to explain how the brain works with respect of faith of all religions and secret orders. Science is interested to know what happen inside ceremony initiation, what kind of token, Marchs, secret words, ritual process performs that impact the human brain. Something happen in candidates and science will meet inside in the future to explain with scientific words without change and respect ancient traditions to be become human being that love human progress with liberty, equality and fraternity.

\section{Acknowledgments}

We thanks, recognize and appreciate the intensive participation of Zoraida Castillo Ramírez (Past Grand Master of Mexican United Female and Regular Grand Lodge, "Alma Mexicana"), Lilian Rodriguez Hernández (Senior Warden of Alpha and Omega number 33 Lodge and temporal Worshipful Master) and all Masters of Alpha and Omega Lodge Number 33 in Mexico City. Special thanks for Yolanda Tovar Ortega (Past Master of Alpha and Omega number 33 Lodge) who coordinate all contacts and the hermetic ceremony. Our recognition for the order to allow us carry out the first meeting between Freemasonry and neuroscience research.

\section{References}

1. Knight C, Lomas R (2003) The book of Hiram, freemasonry Venus and the secret key to the life of Jesus. Sterling publishing.

2. Harari YN (2011) Sapiens. A brief History of humankind.

3. Díaz G, Rodgers A (1993) The Codex Borgia. Dover's publication, inc, Mineola New York, 1993.

4. Nuttall Z (1975) The codex nuttall. Dover's publication, INC, New York.

5. del Castillo BD (1568) The true history of the conquest of Mexico.

6. de Sahagún FB. General history of the things of new Spain.

7. Jennings G, Aztec

8. McNamara P (2011) Religion experience. Volume 2 (Rites to become possessed, Rites to exorcise "Demons").

9. Wesley J (2011) Wildman. Religious and spiritual experience. Cambridge.

10. McNamara P (2006) Where god and science meet, Volumes I, II and III. Greenwood publishing group.

11. Newman B (1998) Possessed by the Spirit: Devout women, demoniacs, and the apostolic life in the thirteenth century the University of Chicago press. Speculum 73: 733-770.

12. https://www.darpa.mil/program/our-research/darpa-and-the-brain-initiative.

13. Binder JR, Frost JA, Hammeke TA, Cox RW, Rao SM, et al. (1997) Human brain language areas identified by functional magnetic resonance imaging. The Journal of Neuroscience 17: 353-362. 
14. www.braingate2.org (Joel Voldman MIT, John Hildebrand UA Monkeys manipulando robots con el pensamiento. Miguel Nicholai, Duke University, 2002 Carolina del Norte).

15. Harari YN (2016) Homo deus. A brief history of tomorrow.

16. Harari YN. 21 lessons for the $21^{\text {st }}$ century. Spiegel.

17. Hallett M (2007) Transcranial magnetic stimulation: A primer. Neuron Prime

18. Blanke O, Arzy S (2005) The out-of-body experience: disturbed self-processing at the temporo-parietal junction. The Neuroscientist 11: 16-24.

19. Metzinger T (2005) Out-of-body experiences as the origin of the concept of a "soul". Mind \& Matter 3: 57-84.
20. Arzy S, Thut G, Mohr C, Michel CM, Blanke O (2006) Neural basis of embodiment: Distinct contributions of temporoparietal junction and extrastriate body Area. The Journal of Neuroscience 26: 8074-8081.

21. Aspell JE, Blanke O (2009) Chapter 5 of the book: Understanding the out-of-body experience from a neuroscientific perspective. Psychological scientific perspectives on out of body and near-death experiences. CHL

22. Blakeslee S (2007) Studies report inducing out-of-body experience. The New York Times. 2007 August 24.

23. Bergström J, Mottelson A, Muresan A, Hornbæk K (2019) Tool extension in humancomputer interaction. CHI. 2019, pp: 1-11.

Copyright: $(02021$ Vázquez JLM. This is an open-access article distributed under the terms of the Creative Commons Attribution License, which permits unrestricted use, distribution, and reproduction in any medium, provided the original author and source are credited. 